\title{
Psychological Distress and Quality of Sleep among Urban Community People during COVID-19 Pandemic
}

\author{
Shobha Laxmi Bajracharya ${ }^{1}$, Bimala Panthee ${ }^{2}$ \\ ${ }^{1}$ Associate Professor, Patan Academy of Health Sciences, School of Nursing and Midwifery, Lalitpur Nursing \\ Campus, Sanepa, Lalitpur, Nepal. \\ ${ }^{2}$ Assistant Professor, Lalitpur Nursing Campus \\ Corresponding Author: Shobha Laxmi Bajracharya
}

\begin{abstract}
Introduction: Corona Virus Disease (COVID-19) had spread all over the world resulting in a large number of deaths. As COVID-19 is highly contagious and directly threatens life, it has caused high level of distress around the globe and impacts quality of sleep as well. This study aimed to analyse psychological distress and quality of sleep during COVID-19pandemic among community people.

Methods: A cross-sectional analytical study was conducted to find out psychological distress and sleep quality among 360 community people residing in Lalitpur, Nepal during COVID-19 pandemic from May to June 2021. Proportionate stratified and snowball sampling techniques were used to select the sample from each stratum. Data were collected through telephone interview using K6 Psychological Distress Scale and sleep quality scale. Data were analysed using descriptive and inferential statistics.

Results: Moderate to high psychological distress was found among $40 \%$ and $79.7 \%$ had good to excellent sleep. Gender and marital status had significant association with distress and history of COVID-19 had significant association with sleep quality at $95 \%$ of significance level ( $\mathrm{p}$-value=.00, $.00, .00)$ respectively. Psychological distress and sleep quality had significant negative relationship $(\mathrm{r}=-.46, \mathrm{p}=.00)$.

Conclusion: Based on the findings of this study, it can be concluded that urban community people had low distress and most of the respondents had good sleep quality. Gender, marital status and history of COVID-19 were associated with distress level and sleep quality. Negative relationship between distress level and sleep quality suggests that there is a need to take consideration of distress level of community people so that their sleep quality can be promoted.
\end{abstract}

Keyword: Community, COVID-19 pandemic, Nepal, Psychological distress, Sleep quality

\section{INTRODUCTION}

Corona Virus Disease (COVID-19) was first reported in Wuhan, China in December 2019and had spread all over the world resulting in a large number of hospitalizations and deaths ${ }^{[1]}$. Apart from the evident physical symptoms in covid-19 infected cases, it has caused serious damage to public mental health. ${ }^{[2]}$ As COVID-19 is highly contagious, devastating and uncertainty of eradication, the long term consequences of this pandemic situation on mental health and well being at personal and population level are manifold. [3] For instance, cognitive distress, psychological distress, anxiety and fear in the society ${ }^{[4]}$. Psychological distress is defined as broader manifestation of mental health related problems that are characterized by depression and anxiety symptoms and known to continue to show severity with stress related concerns. ${ }^{[5]}$ High levels of 
psychological distress are indicative of impaired mental health of the population. ${ }^{[6]}$

As of August 18, 2021, the total case of COVID-19 was208,773,256 with $4,384,989$ deaths worldwide and 739907 total cases with 10,396 deaths in Nepal ${ }^{[7]}$ where the first death of COVID-19 patient was on March 28, $2020^{[8]}$. Covid-19 pandemic is still evolving in Nepal. ${ }^{[7]}$ First case was detected in January $23^{[8]}$ which created unprecedented health and economic impact. Individuals or communities experience mental instability along with social and economic losses which might precipitate as mental stress, anxiety and depression. ${ }^{[9]}$ As COVID-19 is a disease that directly threatens life and concerns of getting infected, sleep disorders were reported in the general population ${ }^{[10]}$. Heightened level of anxiety and its related conditions during covid-19 pandemic have been equally as infectious as the corona virus itself which impacts quality of sleep as well. ${ }^{[11,12]}$

An online based cross-sectional survey conducted among 7,236 participants during COVID-19 outbreak in China showed that the overall prevalence of generalized anxiety disorder (GAD) was $35.1 \%$ and poor sleep quality was $18.2 \%$. Young people aged $<35$ years reported a significantly higher prevalence of GAD symptoms than older people. Healthcare workers were more likely to have poor sleep quality than other professionals. ${ }^{[13]}$ Another study conducted among 1242 residents of Wuhan China during covid-19 pandemic showed that $27.5 \%$ had anxiety, $29.3 \%$ had depression and $30 \%$ had sleep disorder. ${ }^{[14]}$ Another online cross-sectional study among 1,427 respondents regarding the impact of COVID-19 pandemic on the mental health of the adult population in Bangladesh showed the prevalence of anxiety symptoms was $33.7 \% .^{[15]}$

Similarly, in Nepal among 349 participants, $34.1 \%$ showed depression and $31.2 \%$ showed anxiety and the distress level was higher among female and health care professionals. population. ${ }^{[16]}$ Another study conducted in all 7 provinces of Nepal on psychological distress in Nepalese residents during covid-19 pandemic: a community level survey among 410 participants showed $11 \%$ had mild to moderate distress and $0.5 \%$ had severe distress. ${ }^{[9]}$

Poor sleep leads to impairment in attention and memory, increases irritability and emotional instability which leads to anxiety, depression and even suicide. ${ }^{[17]}$ These problems should be addressed quickly and properly and attention must be paid on time in order to overcome and or prevent these problems. Therefore, the aim of the study was to analyze psychological distress, quality of sleep and their associated factors during COVID-19pandemic among urban community people.

\section{MATERIALS AND METHODS}

This was a cross-sectional analytical study carried out among 360 community people residing in three wards (ward 6, 20, and 23) of Lalitpur Metropolitan City, Nepal during COVID-19 pandemic. The sample size was calculated using Cochran formula. These three wards consisted total number of 8407 permanent residents 18 to 60 years of age. All those residents were the study population. Proportionate stratified sampling technique was used to select the sample from each stratum. Snowball sampling technique was used to select the sample until the sample size was achieved from May 2021 to June 2021. Permanent residents of aged 18 to 60 years in Ward no. 6, 20 and 23 of Lalitpur Metropolitan City who were willing to participate in the study were included in the study. Permanent residents whose telephone number was not available and who reported that they were diagnosed as depression, anxiety or other mood disorders and on medication for the specific problem were excluded. out of 8407

The sample size was calculated 360 


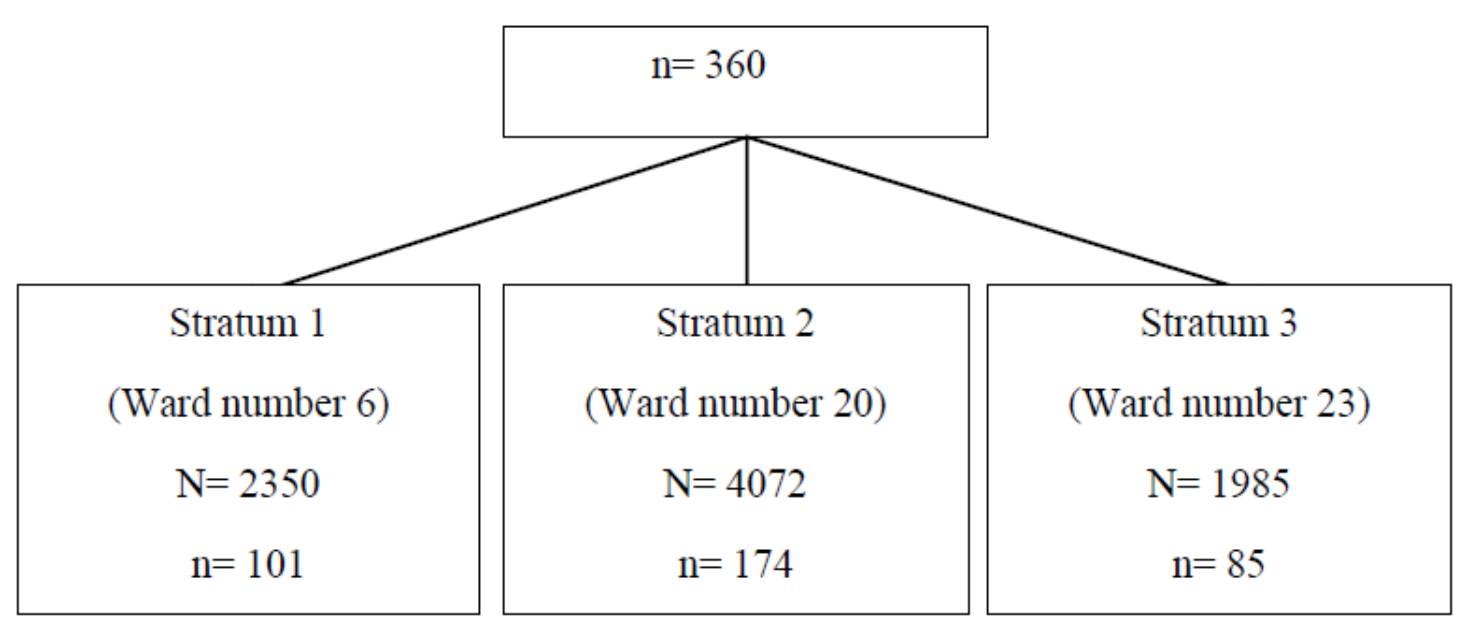

\section{Data collection instruments}

Data collection instrument used for this study was consisted of three parts:

Part-I consisted of self developed structured questionnaire to assess sociodemographic characteristics that included age, gender, educational status, occupation, marital status, and history of covid-19 positive (self/family member).

Part-II consisted of Kessler 6 (K6) Psychological Distress Scale. [18] The Kessler 6 (K6) Psychological Distress Scale is the brief anxiety and depression screening scale which consists of 6 items. It is a standardized validated tool for non-specific psychological distress. Nepali version scale was used to measure psychological distress among community people. The Cronbach's alpha coefficient for Nepali version is .81 . ${ }^{[19]} \mathrm{K} 6$ is a 5-point Likert scale ranging from 0 (never) to 4 (always) to establish how often an individual has experienced psychological distress over the previous 30 days. Total score ranges from 0 to 24 . The cut off score of 5 or less than 5 was taken as no distress, 6-13 as moderate distress and $>13$ as severe distress. ${ }^{[20]}$

Part-III consisted of a single-item sleep quality scale (SQS), ${ }^{[21]}$ was developed as a simple and practicable sleep quality assessment tool. Test re-tests reliability coefficients of the Sleep Quality Scale was 0.91. Intra-class correlation coefficient (ICC) for test-retest reliability was .81. Single item sleep quality scale was used to assess the sleep quality. It is an 11 point rating scale where 0 indicates terrible sleep and 10 indicates excellent sleep. The score was categorized as: $0=$ terrible sleep, $1-3=$ poor sleep, 4-6 = fair sleep, 7-9 = good sleep and $10=$ excellent sleep. Face validity of the translated version of Nepali language tool was maintained.

Data were collected through telephone interview. Initial participants' phone number was obtained from the chair of each ward. After that each participant was asked to tell another person's phone number whom they know. It took about 10 minutes to complete the interview. The respondents' right was protected by obtaining informed verbal consent by using PAHS Generic Form after explaining about the study, before collecting the data. Data was collected by the Principal Investigator.

Ethical approval was obtained from Institutional Review Committee (IRC), PAHS before conducting the study (IRC approval number Ref: nrs2105071520). Privacy of the participants was assured and the phone number used to conduct the interview was not shared to anyone for any other purposes. Confidentiality of the respondents was maintained by coding and decoding and explaining the participants as the obtained data was used only for study purpose. Anonymity of the respondents was assured by not writing participants' name on the questionnaires and by keeping the collected information confidential in locked file in the computer in a cupboard. 
Shobha Laxmi Bajracharya et.al. Psychological distress and quality of sleep among urban community people during COVID-19 pandemic.

\section{Statistical analysis:}

Data cleaning and analysis was done using Statistical Package of Social Sciences (SPPS) software version 16. Descriptive statistics was used to describe the sample characteristics and prevalence of psychological distress and sleep quality. For analyzing the association between sociodemographic factors and psychological distress as well as quality of sleep, inferential statistics (chi-square) was used. P-value was set at 0.05 . To analyze the correlation between psychological distress and quality of sleep during COVID-19 pandemic, Pearson correlation was used. Correlation is significant at the 0.01 level (2-tailed).

\section{RESULTS}

Table 1: Socio-demographic information of respondents, $\mathrm{N}=360$

\begin{tabular}{|c|c|c|}
\hline Characteristics & Frequency & Percentage \\
\hline \multicolumn{3}{|l|}{ Age in completed years } \\
\hline Below 20 & 20 & 5.5 \\
\hline $20-29$ & 69 & 19.2 \\
\hline $30-39$ & 63 & 17.5 \\
\hline $40-49$ & 90 & 25.0 \\
\hline $50-59$ & 118 & 32.8 \\
\hline \multicolumn{3}{|c|}{ Mean age \pm SD: $40.72 \pm 12.27$} \\
\hline \multicolumn{3}{|l|}{ Gender } \\
\hline Male & 159 & 44.2 \\
\hline Female & 201 & 55.8 \\
\hline \multicolumn{3}{|l|}{ Education } \\
\hline Illiterate & 18 & 5 \\
\hline Can read and write & 16 & 16.9 \\
\hline Primary education & 42 & 11.7 \\
\hline Secondary education & 106 & 29.4 \\
\hline Bachelor & 97 & 26.9 \\
\hline Above Bachelor & 36 & 10 \\
\hline \multicolumn{3}{|l|}{ Marital Status } \\
\hline Unmarried & 93 & 25.8 \\
\hline Married & 258 & 71.7 \\
\hline Widow/Widower & 9 & 2.5 \\
\hline \multicolumn{3}{|l|}{ Occupation } \\
\hline Service & 90 & 25 \\
\hline Business & 119 & 33.1 \\
\hline Home maker & 81 & 22.5 \\
\hline Labor & 6 & 1.7 \\
\hline Agriculture & 4 & 1.1 \\
\hline Students & 47 & 13.1 \\
\hline Others (Social worker) & 13 & 3.6 \\
\hline \multicolumn{3}{|l|}{ Health professional } \\
\hline Yes & 20 & 5.6 \\
\hline No & 340 & 94.4 \\
\hline \multicolumn{3}{|c|}{ History of COVID-19 in family } \\
\hline Yes & 125 & 34.7 \\
\hline No & 235 & 65.3 \\
\hline \multicolumn{3}{|c|}{ If yes, Affected person $(n=125)$} \\
\hline Self & 58 & 46.4 \\
\hline Family member & 67 & 53.6 \\
\hline
\end{tabular}

Table 2: Level of psychological distress, $\mathbf{N}=\mathbf{3 6 0}$

\begin{tabular}{|l|l|l|}
\hline Characteristics & Frequency & Percentage \\
\hline No or low distress (0-5) & 216 & 60.0 \\
\hline Moderate distress (6-13) & 127 & 35.3 \\
\hline High distress (14-24) & 17 & 4.7 \\
\hline Mean score \pm SD: $4.62 \pm 4.26$ & \multicolumn{2}{|l}{} \\
\hline
\end{tabular}

Table 3: Level of sleep quality, $N=360$

\begin{tabular}{|l|l|l|}
\hline Characteristics & Frequency & Percentage \\
\hline Poor sleep & 5 & 1.4 \\
\hline Fair sleep & 68 & 18.9 \\
\hline Good sleep & 216 & 60.0 \\
\hline Excellent sleep & 71 & 19.7 \\
\hline Mean score \pm SD: $7.87 \pm 1.68$ & \\
\hline
\end{tabular}

Table 4: Association between socio-demographic variables and psychological distress, $\mathrm{N}=360$

\begin{tabular}{|c|c|c|c|c|}
\hline \multirow{2}{*}{ Factors } & \multicolumn{4}{|c|}{ Level of Psychological distress } \\
\hline & No distress & Distress & $\chi^{2}$ & $\begin{array}{l}\text { p- } \\
\text { value }\end{array}$ \\
\hline \multicolumn{5}{|l|}{ Age } \\
\hline$<40$ years & $86(39.8 \%)$ & $66(45.8 \%)$ & \multirow[t]{2}{*}{1.28} & \multirow[t]{2}{*}{.25} \\
\hline $\begin{array}{l}40 \text { years and } \\
\text { above }\end{array}$ & $130(60.2 \%)$ & $78(54.2 \%)$ & & \\
\hline \multicolumn{5}{|l|}{ Gender } \\
\hline Male & $105(66.0 \%)$ & $54(34.0 \%)$ & \multirow[t]{2}{*}{11.828} & \multirow[t]{2}{*}{.00} \\
\hline Female & $111(55.2 \%)$ & $90(44.8 \%)$ & & \\
\hline \multicolumn{5}{|l|}{ Education } \\
\hline $\begin{array}{l}\text { Illiterate and can } \\
\text { read and write } \\
\text { only }\end{array}$ & $47(59.4 \%)$ & $32(40.5 \%)$ & \multirow[t]{2}{*}{.011} & \multirow[t]{2}{*}{.91} \\
\hline $\begin{array}{l}\text { Primary } \\
\text { education and } \\
\text { above }\end{array}$ & $169(60.1 \%)$ & $112(39.9 \%)$ & & \\
\hline \multicolumn{5}{|l|}{ Marital status } \\
\hline Unmarried & $45(48.4 \%)$ & $48(51.6 \%)$ & \multirow[t]{2}{*}{7.046} & \multirow[t]{2}{*}{.00} \\
\hline Married & $171(64.0 \%)$ & $96(36.0 \%)$ & & \\
\hline \multicolumn{5}{|c|}{ Health professional } \\
\hline Yes & $15(75.0 \%)$ & $5(25.0 \%)$ & \multirow[t]{2}{*}{1.985} & \multirow[t]{2}{*}{.15} \\
\hline No & $201(59.1 \%)$ & $139(40.9 \%)$ & & \\
\hline \multicolumn{5}{|c|}{ History of COVID-19 } \\
\hline Yes & $74(59.2 \%)$ & $51(40.8 \%)$ & \multirow[t]{2}{*}{.015} & \multirow[t]{2}{*}{.82} \\
\hline No & $142(60.0 \%)$ & $93(39.6 \%)$ & & \\
\hline
\end{tabular}

The mean age of the participants was $40.72 \pm 12.27$ years and about $56 \%$ were female and $72 \%$ were married. However, only $5.6 \%$ were health care professionals and $35 \%$ had history of COVID-19 in the family (Table 1). Regarding the level of psychological distress, $60 \%$ of the participants did not have distress (Table 2) and about $80 \%$ had good to excellent sleep (Table 3). Regarding the factors associated with psychological distress, gender had significant association with psychological distress where $45 \%$ female had psychological distress than $34 \%$ male with p-value .00 and unmarried people showed higher distress with p-value .00 (Table 4). In addition, history of COVID-19 had significant association with sleep quality 
with p-value .00 (Table 5). Psychological distress and sleep quality had significant negative relationship ( $\mathrm{r}=-.46, \mathrm{p}=.00)$. It means the community people, who had high level of psychological distress, had poor sleep quality (Table 6).

Table 5: Association between socio-demographic variables and quality of sleep, $N=360$

\begin{tabular}{|c|c|c|c|c|}
\hline \multirow{2}{*}{ Factors } & \multicolumn{4}{|c|}{ Quality of sleep } \\
\hline & $\begin{array}{l}\text { Poor to } \\
\text { fair sleep }\end{array}$ & $\begin{array}{ll}\text { Good } & \text { to } \\
\text { excellent } & \\
\text { sleep } & \end{array}$ & $\chi^{2}$ & $\begin{array}{l}\text { p- } \\
\text { value }\end{array}$ \\
\hline \multicolumn{5}{|l|}{ Age } \\
\hline$<40$ years & $33(45.2 \%)$ & $119(41.5 \%)$ & \multirow[t]{2}{*}{.33} & \multirow[t]{2}{*}{.56} \\
\hline $\begin{array}{l}40 \text { years and } \\
\text { above }\end{array}$ & $40(54.8 \%)$ & $168(58.5 \%)$ & & \\
\hline \multicolumn{5}{|l|}{ Gender } \\
\hline Male & $35(47.9 \%)$ & $124(43.2 \%)$ & \multirow[t]{2}{*}{.53} & \multirow[t]{2}{*}{.46} \\
\hline Female & $38(52.1 \%)$ & $163(56.8 \%)$ & & \\
\hline \multicolumn{5}{|l|}{ Education } \\
\hline $\begin{array}{ll}\text { Illiterate } & \text { and } \\
\text { can read and } \\
\text { write only }\end{array}$ & $15(20.5 \%)$ & $64(22.3 \%)$ & \multirow[t]{2}{*}{.10} & \multirow[t]{2}{*}{.74} \\
\hline $\begin{array}{l}\text { Primary } \\
\text { education and } \\
\text { above }\end{array}$ & $58(79.5 \%)$ & $223(77.3 \%)$ & & \\
\hline \multicolumn{5}{|l|}{ Marital status } \\
\hline Unmarried & $22(30.1 \%)$ & $71(24.7 \%)$ & \multirow[t]{2}{*}{.88} & \multirow[t]{2}{*}{.34} \\
\hline Married & $51(69.9 \%)$ & $216(75.3 \%)$ & & \\
\hline \multicolumn{5}{|c|}{ Health Professional } \\
\hline Yes & $2(2.7 \%)$ & $18(6.3 \%)$ & \multirow[t]{2}{*}{1.38} & \multirow[t]{2}{*}{.23} \\
\hline No & $71(97.3 \%)$ & $269(93.7 \%)$ & & \\
\hline \multicolumn{5}{|c|}{ History of COVID-19 } \\
\hline Yes & $35(47.9 \%)$ & $90(31.4 \%)$ & \multirow[t]{2}{*}{7.06} & \multirow[t]{2}{*}{.00} \\
\hline No & $38(52.1 \%)$ & $197(68.6 \%)$ & & \\
\hline
\end{tabular}
level)

Table 6: Correlation between psychological distress and sleep quality, $\mathbf{N}=\mathbf{3 6 0}$

\begin{tabular}{|l|l|l|l|}
\hline Variables & $\begin{array}{l}\text { Psychological } \\
\text { distress }\end{array}$ & $\begin{array}{l}\text { Sleep } \\
\text { quality }\end{array}$ & $\begin{array}{l}\text { p- } \\
\text { value }\end{array}$ \\
\hline $\begin{array}{l}\text { Psychological } \\
\text { distress }\end{array}$ & 1 & .000 \\
\cline { 1 - 3 } Sleep Quality & -.468 & 1 & \\
\hline
\end{tabular}

Note: Correlation is significant at the 0.01 level (2-tailed).

\section{DISCUSSION}

This study aimed to find out the psychological distress and quality of sleep during COVID-19 pandemic among community people.

Regarding the level of psychological distress, three fifth $(60 \%)$ of the respondents had no or low psychological distress followed by more than one third (35.3\%) had moderate distress and only about 5\% had high level of psychological distress. The mean score of distress was 4.26 which fall on no or low distress. However, it is on the lower borderline for moderate distress. The data collection period was during national level lock down which might be associated with the lower level of distress as during this period all the respondents were not supposed to go outside and living with their family member at home. This study finding was similar to a study conducted among 7,236 Chinese public during COVID-19 outbreak in China that showed $35.1 \%$ overall prevalence of generalized anxiety disorder (GAD). ${ }^{[13]}$ This study finding was higher in compared to a study conducted in China among 56,679 general populations during COVID-19 pandemic where anxiety was found among $31.6 \% .{ }^{[23]}$ Another crosssectional study conducted among 1242 residents of Wuhan, China revealed that $27.5 \%$ of the respondents had anxiety. ${ }^{[14]}$

In our study, three fifth of the respondents $(60 \%)$ had good sleep followed by one fifth $(19.7 \%)$ had excellent sleep and one fifth $(20.3 \%)$ of the respondents had poor sleep, the mean score of sleep quality was 7.87 which falls on good sleep category. About $20 \%$ of respondents had poor sleep in this study is similar to the study finding conducted among 7,236 Chinese public during COVID-19 outbreak in China that showed $18.2 \%$ of poor sleep quality. Another cross-sectional study conducted among 1242 residents of Wuhan, China found $30 \%$ of the respondents had sleep disorder. ${ }^{[14]}$ A cross-sectional study conducted among 269 medical students at KIST medical college teaching hospital, Nepal showed higher results as $36.4 \%$ of the respondents had poor quality of sleep. ${ }^{[24]}$ This study finding was contrasted to a study conducted among adults in Turkey during covid-19 positive which showed the prevalence of poor sleep quality was $55.1 \% .{ }^{[25]}$ An another study conducted in Kathmandu valley Nepal among 504 college students showed contrasted finding that $59.1 \%$ of the respondents had poor quality of sleep. ${ }^{[26]}$ Another study conducted among employees of a nursing campus and their spouses in Lalitpur Nepal also showed contrasted finding that $39.1 \%$ had got poor quality of sleep. ${ }^{[27]}$ 
Regarding the factors associated with psychological distress, gender had significant association with psychological distress where $45 \%$ female had psychological distress than $34 \%$ male and unmarried people showed higher distress at $95 \%$ of significance level $(\mathrm{p}<0.05)$. In this study, there was no significant association of age, education, health profession and history of COVID-19 of the respondents with psychological distress at $95 \%$ of significance level ( $p>0.05)$. This study finding was contrasted to a study conducted among 7,236 Chinese public during covid19 outbreak in China showed that there was statistically significant association of age and health profession with the psychological distress. ${ }^{[13]}$

Our study finding showed that there was no significant association of age, gender, education, marital status and health profession with quality of sleep during covid-19 pandemic at $95 \%$ of significance level ( $p>0.05)$. A study conducted among employees of a nursing campus and their spouses in Lalitpur Nepal also showed similar findings as there was no significant association of age, gender and status of respondents with quality of sleep ${ }^{[27]}$ There was a statistically significant association of history of covid-19 of the respondents with the quality of sleep at $95 \%$ of significance level $(p<0.05)$. This study finding is contrasted to the finding of cross-sectional study conducted among 1242 residents of Wuhan, China which found being female was the risk factor for sleep disorder $(\mathrm{OR}=1.36) .{ }^{[14]}$ Another study conducted among 504 students in Kathmandu valley revealed that there was slightly difference between male and female respondents i.e. $55.21 \%$ of male and $65.78 \%$ of female had poor sleep quality. ${ }^{[26]}$

The present study revealed that the psychological distress had negative correlation $(\mathrm{r}=-.46)(\mathrm{p}=.00)$ with quality of sleep meaning that the community people, who had high level of psychological distress, had poor sleep quality.
We recruited community people of urban community who were permanent residents only. Thus, the findings of this study might not be generalized to other people who are not permanent residents. The low level of the distress might be associated with this factor as they had their own residence in the capital city of Nepal. Also, the telephone interview might be associated with response bias as researcher could not relate the answer of the respondents they provided.

\section{CONCLUSION}

Based on the findings of this study, it can be concluded that the distress level of community people during COVID-19 pandemic was not high and most of the respondent's quality of sleep was good. However, psychological distress and sleep quality was different according to gender, marital status and previous history of COVID-19. In addition, psychological distress and sleep quality was significantly negatively correlated suggesting that there is a need to reduce the level of psychological distress using psychosocial measures to have a good quality sleep of community people.

\section{ACKNOWLEDGMENT}

We would like to express our heartfelt gratitude to all the respondents for their participation and cooperation in this study. Similarly, we would like to express our sincere thanks to Dr. Priscilla Samson for necessary help in manuscript writing.

\section{Conflict of Interest: None}

\section{Source of Funding: None}

\section{Ethical Approval: Approved}

\section{Author Contribution}

SLB concept, design, data collection, data analysis, wrote manuscript,

BP concept, design, data analysis, wrote manuscript 
Both authors read and approve the final draft.

\section{REFERENCES}

1. Wang C, Pan R, Wan X, Tan Y, Xu L, Ho $\mathrm{C}$, et al. (2020). Immediate psychological responses and associated factors during the initial stage of the 2019 Coronavirus Disease (COVID-19) epidemic among the general population in China. International Journal of Environmental Research and Public Health, 17(5), 1729. https://doi.org/10.3390/ijerp h1705 1729.

2. Rehman U, Shahnawaz MG, Khan NH, Kharshiing KD, $\cdot$ KhursheedM - GuptaK, et al.Depression, anxiety and stress among Indians in times of Covid-19 lockdown. Community Mental Health Journal, https://doi.org/10.1007/s10597-020-00664-x

3. Dubey $\mathrm{S}$, et al. Psychosocial impact of COVID-19, Diabetes \& Metabolic Syndrome: Clinical Research \& Reviews 14 (2020) 779-788 DOI Google Scholar

4. Shah K, Kamrai D, Mekala H, Mann B, Desai K, Patel RS. (2020) Focus on Mental Health During the Coronavirus (COVID-19) Pandemic: Applying Learnings from the Past Outbreaks. Cureus 12(3): e7405. DOI 10.7759/cureus.7405

5. Liang L, Gao T, Ren H, Cao R, Qin Z, Hu $\mathrm{Y}$, et al. (2020). Post-traumatic stress disorder and psychological distress in Chinese youths following the COVID-19 emergency. J. Health Psychol. 25 (9), 1164$1175 . \quad$ https://doi.org/10.1177/ 1359105320937057.

6. Arvidsdotter T, Marklund B, Kylen S, et al. Understanding persons with psychological distress in primary health care. Scandivanian Journal of Caring Science. 2016; 30:687-94. DOI: 10.1111/scs. 12289

7. Ministry of Health and Population (MoHP). $18^{\text {th }}$ August 2021. Weblink

8. Panthee B, Dhungana S, Panthee N, Gyawali S, Paudel A \&Panthee S. Clinical and epidemiological features of COVID-19 deaths in Nepal. New Microbes and New Infections. 2020, 38,

9. Shrestha DB, et al. Psychological disorders in Nepalese residents during COVID-19 pandemic: a community level survey, BMC Psychiatry 20:491 DOIPubMEDGoogle Scholar
10. Lin, C., Brostr"om, A., Griffiths, M., Pakpour, A., 2020. Investigating mediated effects of fear of COVID-19 and COVID-19 misunderstanding in the association between problematic social media use, psychological distress, and insomnia. Internet Interv. 21 (March), 100345.

11. Wang Y, Yu D, Ye J, Wei W. Study on the public psychological states and its related factors during the outbreak of coronavirus disease (COVID-19) in some regions of China. Psychology, Health \& Medicine. 2021; 26(1):13-22. doi: 10.1080/13548506.2020.1746817

12. Germano C. Mental health crisis: Stress, anxiety, poor sleep \& COVID: What Does the Endocannabinoid System Have to Do With It? https://wholefoodsmagazine.com/blog/ment al-health-crisis-stress-anxiety-poor-sleepcovid/

13. Huang Y, Zhao N. Generalized anxiety disorder, depressive symptoms and sleep quality during COVID-19 outbreak in China: a web-based cross-sectional survey, Psychiatry Research.2020; 288. doi: https://doi.org/10.1016/j.psychres.2020.112 954

14. Fu W, Wang C, ZouL, Guo Y, Lu Z, Yan S et al. Psychological health, sleep quality and coping styles to stress facing the COVID-19 in Wuhan, China, Translational Psychiatry (2020) 10:225,DOIGoogle Scholar

15. Hasan MD, Sayeed A, Kundu S, Christopher E, Hasan T, Begam MR et al., The impact of the COVID-19 pandemic on the mental health of the adult population in Bangladesh: A nationwide cross-sectional study, International Journal of Environmental Health Research (2020). DOI10.1080/09603123.2020.1802409https:/ /www.tandfonline.com/doi/full/10.1080/096 03123.2020.1802409

16. Sigdel A, Bista A, Bhattarai $\mathrm{N}$ et al. Depression, Anxiety and depression-anxiety comorbidity amid COVID-19 pandemic: An online survey conducted during lockdown in Nepal,

https://doi.org/10.1101/2020.04.30.2008692 6DOIGoogle Scholar

17. Butcher A, The undeniable link between sleep and mental health. August 14, 2019. Weblink

18. Kessler RC, Barker PR, Colpe LJ, Epstein JF, Gfroerer JC, Hiripi E et al. Screening for 
serious mental illness in general population, Archive General Psychiatry (2003) 60:184189 Google Scholar

19. Panthee B, Shimazu A, Kawakami N, Validation of Nepalese version of work engagement scale, Journal of Occupational Health (2014) 56:421-9 DOI Google Scholar

20. Pun KM, Panthee B, Samson P, \& Bajracharya SL. Psychological distress among adults of an urban community of Lalitpur District, Nepal. International Journal of Health Sciences and Research DOI:

https://doi.org/10.52403/ijhsr.20210729

Vol.11; Issue: 7; July 2021 Website: www.ijhsr.org

21. Snyder E, Cai B, DeMuro C, Morrison MF, Ball W. A new single-item sleep quality scale: Results of psychometric evaluation in patients with chronic primary insomnia and depression. Journal of Clinical Sleep Medicine (2018) 14:11, DOIGoogle Scholar

22. Atroszko PA, Baginska P, Mokosinska M, Sawacki A, Atroszko B, Validity and reliability of single item self report measures of general quality of life, general health and sleep quality, Comparative European Research ( CER) 2015 (11) Google Scholar

23. Shi L, Lu Z, Que J, Huang X, Liu L, Ran M, Gong Y, Yuan K, Yan W, Sun Y, Shi J, Bao Y, Lu L, Prevalence of and risk factors associated with mental health symptoms among the general population in China during the coronavirus disease 2019 pandemic, JAMA Network Open. 2020; 3(7):e2014053.

doi:10.1001/jamanetworkopen.2020.14053

(Reprinted)
24. Maharjan N, KarkiPK, Adhikari B, Bhaila A, Shrestha H. Association between sleep duration, sleep quality and body mass index in medical students. JCMC, 2020. 10(34), 34-38. IAvailable online at: www.jcmc.com.np ISSN 2091-2889 (Online) SN

25. Duran S, Erkin O, Psychologic distress and sleep quality among adults in Turkey during the COVID-19 pandemic. Progress in Neuropsychopharmacology \&Biological Psychiatry 107 (2021) 110254 journal homepage:

www.elsevier.com/locate/pnphttps://doi.org/ 10.1016/j.pnpbp.2021.1102542091-2889

(Online) ISSN 2091- 2091-2412 (Print412 (Print)

26. Khadka R, Bista S, Baskota S, Poudel L, Gurung M. Sleep quality among college students in Kathmandu Valley, Nepal. Nepal Med J 2019. 02(03), 1-4 DOI: 10.37080/nmj.61

https://www.researchgate.net/publication/34 2336629

27. Bajracharya SL, Samson P, KC S, Pun KP. COVID-19 anxiety and quality of sleep among employees of a Nursing Campus and their spouses. International Journal of Health Sciences and Research 2021 11(6) 263-270.

DOI:https://doi.org/10.52403/ijhsr.2021063 9

How to cite this article: Bajracharya SL, Panthee B. Psychological distress and quality of sleep among urban community people during COVID-19 pandemic. Int J Health Sci Res. 2021; 11(9):125-132. DOI: https://doi.org/10. 52403/ijhsr.20210919 